\title{
Versatile Surface Channel Concept for Microfluidic Applications
}

\author{
M. Dijkstra, M.J. de Boer, J.W. Berenschot, T.S.J. Lammerink, \\ R.J. Wiegerink and M. Elwenspoek \\ $\mathrm{MESA}^{+}$Research Institute, University of Twente \\ PO Box 217, 7500 AE Enschede, The Netherlands \\ m.a.dijkstra@ewi.utwente.nl
}

\begin{abstract}
MEMS fluidic devices often require the integration of sensor/actuator structures with freely suspended microchannels. This article presents a versatile microchannel fabrication concept, allowing for easy fluidic interfacing to the microchannel and integration of sensor/actuator structures in close proximity to the fluid. Several micro-fluidic device structures have been fabricated, demonstrating the concept.
\end{abstract}

Keywords: microchannels, micro-fluidics, lab-on-chip

\section{INTRODUCTION}

The ever continuing downscaling of MEMS fluidic devices requires the fabrication of small microchannels with the ability of integrating various types of solid-state sensor/actuator structures. Often these structures need to be in close proximity to the fluid. For instance, in thermal applications the fluid should be heated or the fluid temperature has to be measured. Furthermore, thermal isolation from the heat-conducting substrate requires the ability for the microchannels to be suspended freely [1].

Freely suspended microchannels are also being used for fluid-mechanical resonance applications [2,3], requiring mechanically strong channels preventing stiction of the channels due to bending.

Microchannels should also be mechanically strong for high-pressure applications with proper fluidic interfacing to the macro-world, possibly with zero dead-volume, while the interfacing to the microchannel and the microchannel itself should be chemically inert for various chemical applications.

Microchannels fabricated by bulk-bond micromachining and surface micromachining are somewhat limited in fulfilling mentioned requirements. For instance, integration of sensor/actuator structures in close proximity to the fluid is usually difficult for freely suspended microchannels fabricated using bulk micromachining and high temperature bonding techniques [4]. Surface micromachined channels allow for easy integration of sensor/actuator structures, but require time-consuming release of a sacrificial layer and low etch rate of the sensor/actuator materials for the sacrificial etchant used. A major disadvantage of surface micromachined channels is the large hydraulic resistance due to the limitation in channel height, determined by the sacrificial layer.

Buried channel technology (BCT) is a good alternative in fabricating mechanical strong freely suspended circular microchannels deep below the substrate surface [5]. However, the integration of sensor/actuator structures in close proximity to the fluid is impossible. Furthermore, fluidic interfacing is difficult introducing dead-volumes. These limitations can be overcome by making channels directly below the substrate surface [5-8].

A versatile technological concept is presented, called surface channel technology (SCT), combining freely suspended chemical resistant low-stress $\mathrm{Si}_{\mathrm{X}} \mathrm{N}_{\mathrm{Y}}$ microchannels directly below the substrate surface with excellent properties for fluidic interconnection and sensor/actuator integration in close proximity to the fluid.

\section{SURFACE CHANNEL TECHNOLOGY}

The basic concept behind surface channel technology (SCT) is to make low stress $\operatorname{Si}_{X} N_{Y}$ channels directly below the substrate surface, which are completely sealed after processing, leaving a planar substrate for further processing. This allows for the pattern transfer by lithography and depositing of sensor/actuator materials, without any material being accumulated inside the microchannels. The microchannels are released and inlets and outlets are created using a post-processing scheme.

\section{II.1 SURFACE MICROCHANNELS}

Surface microchannels are fabricated using a one-mask process scheme (figure 1). The mask-layout defines etch holes combined into segmented lines, with each line defining a microchannel. The etch holes are designed $2 \mu \mathrm{m}$ in width and varying in length from $2 \mu \mathrm{m}$ up to $15 \mu \mathrm{m}$, with $2 \mu \mathrm{m}$ separation between etch holes.

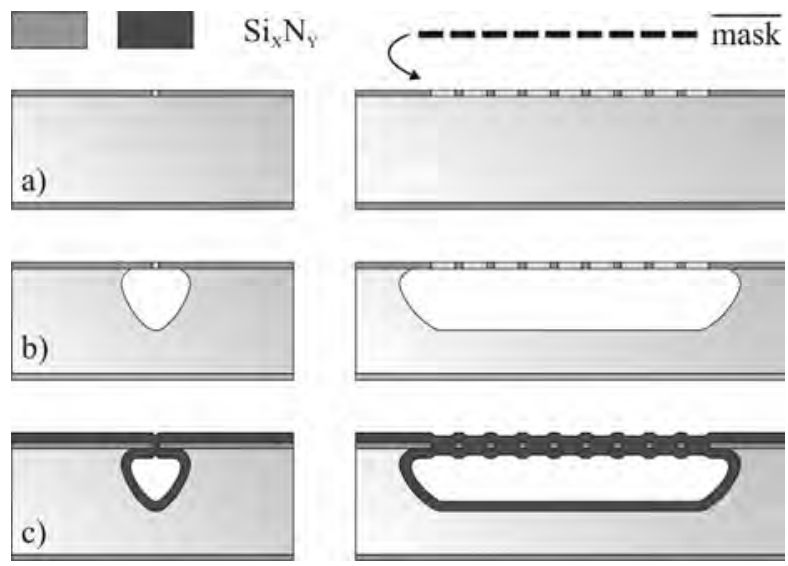

Figure 1. Surface microchannel process scheme, applying a single mask defining etch holes in the $\mathrm{Si}_{\mathrm{X}} \mathrm{N}_{\mathrm{Y}}$ layer. 
The mask layout is transferred into a $500 \mathrm{~nm}$ tensile lowstress $(<300 \mathrm{MPa}) \mathrm{Si}_{\mathrm{X}} \mathrm{N}_{\mathrm{Y}}$ layer deposited on a silicon wafer by LPCVD, defining the etch holes used for microchannel etching (figure 1a). The channels are etched isotropically through the etch holes, leading to coalescence of neighbouring etch surfaces, resulting in long channels with a circular profile (figure 1b). The arrangement of etch holes determines the final size and shape of the microchannel network, including microchannel crossings and cavities (figure 2).

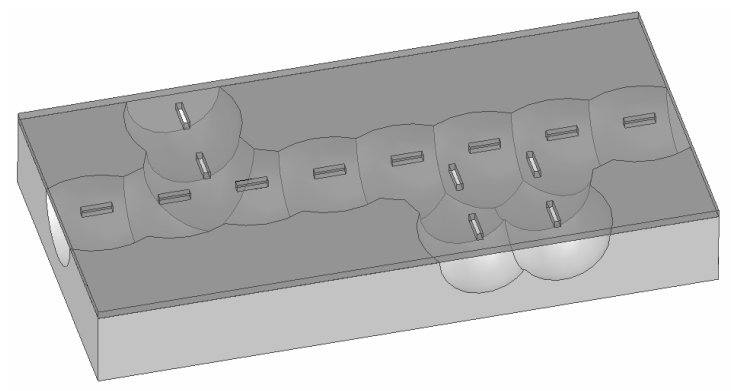

Figure 2. Surface microchannels formed by the coalescence of etch surfaces.

The advantage of using $2 \mu \mathrm{m}$ wide etch holes in the overhanging $\mathrm{Si}_{\mathrm{X}} \mathrm{N}_{\mathrm{Y}}$ membranes is that it can be properly sealed by a second LPCVD low-stress $\mathrm{Si}_{\mathrm{X}} \mathrm{N}_{\mathrm{Y}}$ deposition (figure 1c). Additionally the $\mathrm{Si}_{\mathrm{X}} \mathrm{N}_{\mathrm{Y}}$ layer is conformally coated on the inside surfaces of the microchannels. The $\mathrm{Si}_{\mathrm{X}} \mathrm{N}_{\mathrm{Y}}$ membranes are flat after sealing and sufficiently strong for further processing, allowing for the integration of sensor/actuator structures.

\section{II.2 POST-PROCESSING}

After the sensor/actuator structures have been fabricated the microchannels are ready to be released. Figure 3 shows the possibility of releasing the microchannels by $\mathrm{KOH}$ wet-etching.
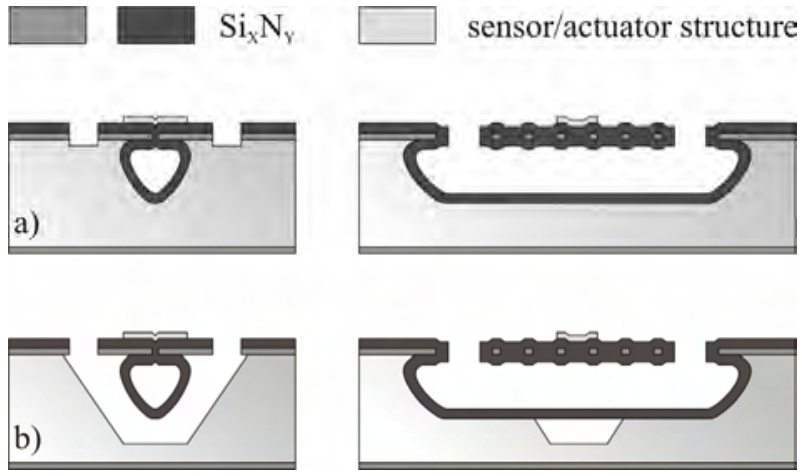

Figure 3. Process scheme for the release of surface microchannels by $\mathrm{KOH}$ etching.

The $\mathrm{Si}_{\mathrm{X}} \mathrm{N}_{\mathrm{Y}}$ layer is patterned creating inlets and outlets, while etch-windows are opened to the bulk silicon using the same mask (figure 3a). The microchannels are released through the etch-windows by $\mathrm{KOH}$ etching (figure $3 \mathrm{~b}$ ). If required the microchannels can also be released by $\mathrm{KOH}$ etching from the backside of the wafer using an additional mask.

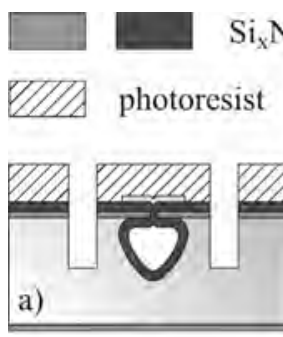

sensor/actuator structure
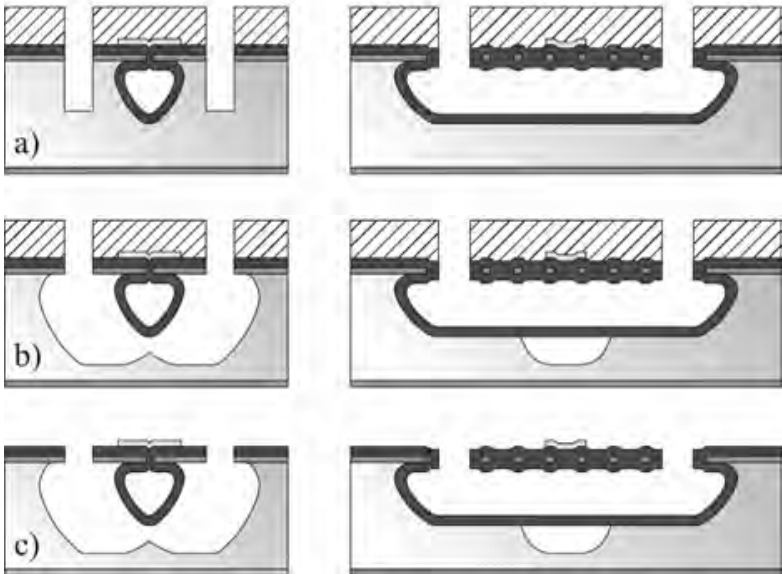

Figure 4. Process scheme for the release of surface microchannels by plasma etching.

Figure 4 shows the possibility for the release of the surface microchannels using non-directional $\mathrm{SF}_{6}$ plasma. The sensor/actuator structures are protected by a thick photoresist layer used as mask during the release of the microchannels. An initial directional plasma etch of the bulk silicon is performed, minimising the lateral under etch (figure 4a), before the actual release of the microchannel by the $\mathrm{SF}_{6}$ plasma (figure $4 \mathrm{~b}$ ). Finally, the photoresist is removed (figure 4c).

The protection of the sensor/actuator structures by photoresist during $\mathrm{SF}_{6}$ plasma release allows for the integration of nearly any type of sensor/actuator structure. Release by $\mathrm{KOH}$ etching is straightforward, but the etch solution is aggressive against certain metals and the microchannels need to be cleaned, removing remaining $\mathrm{KOH}$ etch solution after processing.

\section{CHANNEL ETCHING}

An isotropic etch process is required for the fabrication of the microchannels, aiming for good channel uniformity across the wafer. Either an $\mathrm{HF} / \mathrm{HNO}_{3}$ wet-chemical etch process or a non-directional high-density $\mathrm{SF}_{6}$ plasma with zero-bias can be used.

Wet-chemical etching using $\mathrm{HF} / \mathrm{HNO}_{3}$ has a significant loading effect on microchannel uniformity, requiring compensation structures [9]. Selectivity against $\mathrm{Si}_{X} \mathrm{~N}_{\mathrm{Y}}$ is low and pressure build-up inside the channels might lead to cracking of the $\mathrm{Si}_{\mathrm{X}} \mathrm{N}_{\mathrm{Y}}$ membranes during etching.

A high-density $\mathrm{SF}_{6}$ plasma with zero self-bias offers a good alternative to wet-chemical etching. A preliminary study was conducted using the Adixen AMS 100 SE with photoresist as mask (figure 5). An isotropic profile was expected due to the small $2 \mu \mathrm{m}$ etch holes. However, a significant anisotropic etch effect was observed (figure 5). In general it was observed that etching at lower pressure resulted in a more isotropic channel profile. 


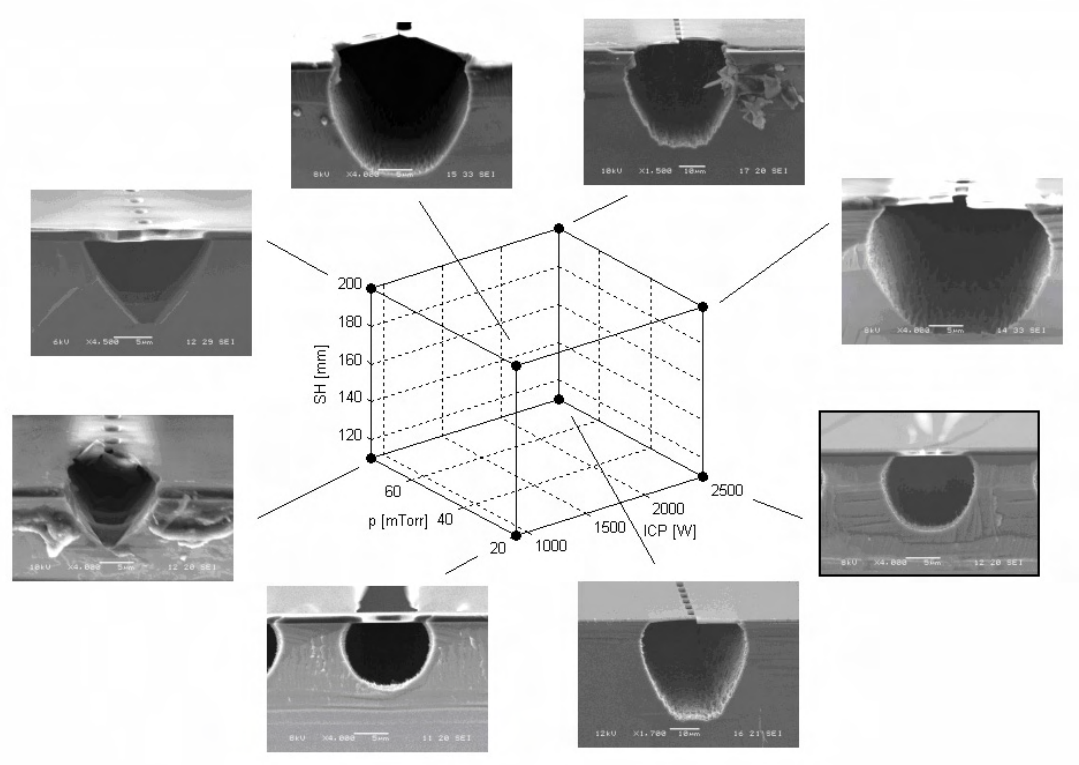

Figure 5. Channel profile parameter study using Adixen AMS $100 \mathrm{SE}$, applying fixed plate power $(\mathrm{CPP})=0 \mathrm{~W}$, $\mathrm{SF}_{6}=400 \mathrm{sccm}$ and $\mathrm{T}_{\text {electrode }}=20^{\circ} \mathrm{C}$ for 10 minutes etching at about $10 \%$ loading. Substrate height (SH), chamber pressure (p) and ICP power were varied.

Additional etch experiments have to be done in order to etch a perfect isotropic channel profile with smooth sidewalls using a high-density $\mathrm{SF}_{6}$ plasma.

The best channel profile, with good uniformity across the wafer, was obtained applying an ICP of $2500 \mathrm{~W}$ at $20 \mathrm{mTorr}$ pressure with a substrate height of $110 \mathrm{~mm}$. A vertical etch speed of $1.5 \mu \mathrm{m} \cdot \mathrm{min}^{-1}$, with a relative lateral etch speed of 0.75 was measured for microchannels etched with these settings for 10 minutes. An etch rate of $25 \mathrm{~nm} \cdot \mathrm{min}^{-1}$ was measured for $\mathrm{Si}_{\mathrm{X}} \mathrm{N}_{\mathrm{Y}}$.

\section{PROCESS RESULTS}

Surface microchannels were fabricated starting with the deposition of a low-stress $500 \mathrm{~nm} \quad \mathrm{Si}_{\mathrm{X}} \mathrm{N}_{\mathrm{Y}}$ layer by LPCVD. Microchannels were etched using the Adixen AMS 100 SE with the described process for a period of 10 minutes.

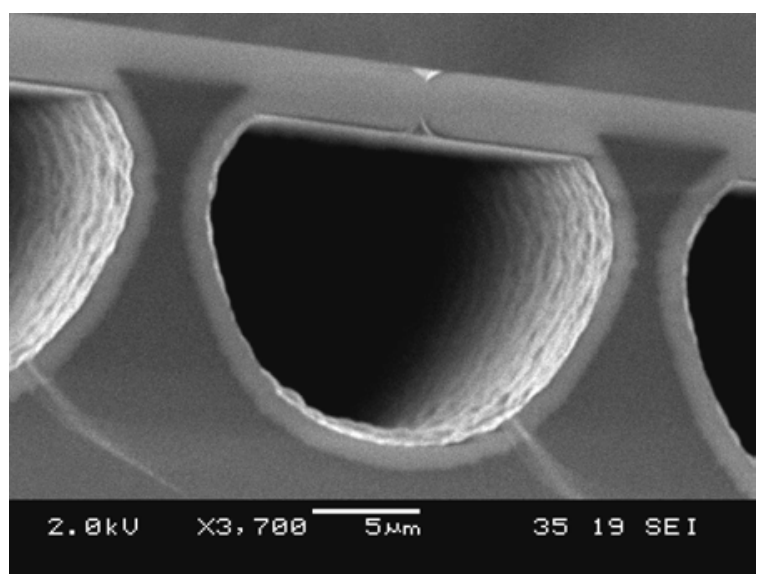

Figure 6. Cross-section of sealed surface microchannel.
The channels were perfectly sealed and covered on the sidewalls with a $1.2 \mu \mathrm{m}$ thick $\mathrm{Si}_{\mathrm{X}} \mathrm{N}_{\mathrm{Y}}$ layer deposited by LPCVD (figure 6).

The surface microchannels were released by $\mathrm{KOH}$ etching and inlets and outlets were created on the frontside of the wafer. An additional mask was used for the release of the surface microchannels from the backside of the wafer.

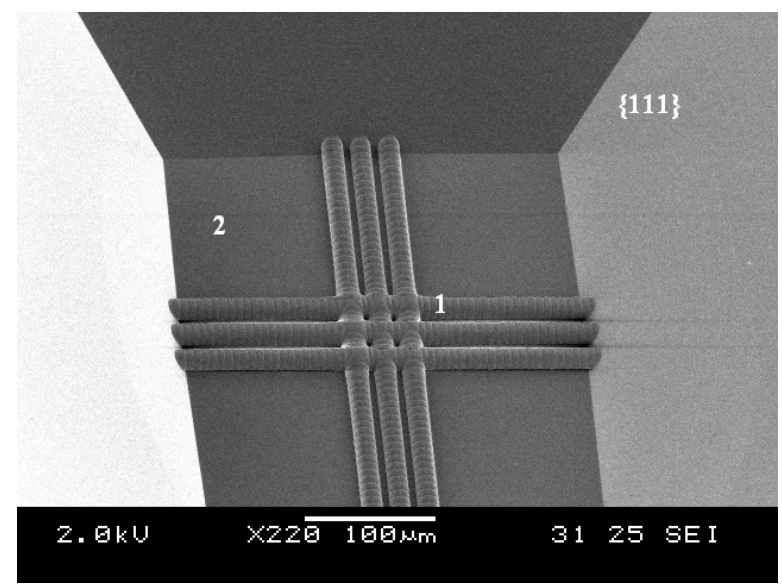

Figure 7. Device structure for microreactors, with 1) crossing microchannels and 2$) \mathrm{Si}_{X} \mathrm{~N}_{Y}$ membrane.

Figure 7 shows crossing microchannels observed form the backside of the wafer. The microchannels are emerging from $\{111\}$-planes created by $\mathrm{KOH}$ etching from the backside. The microchannels are fixed to the $\mathrm{Si}_{X} \mathrm{~N}_{\mathrm{Y}}$ membrane layer on the frontside of the wafer.

The structure demonstrates the possibility in creating microfluidic networks for microreactor applications. A range of designs can be realised, including: reactor chambers, static micromixers and micro heat exchangers. 
Integration of metal heaters on top of freely suspended microchannels allows for the efficient heating of the fluid, while rapid cooling to ambient temperature can be achieved by the embedding of microchannels in the bulk silicon of the substrate.

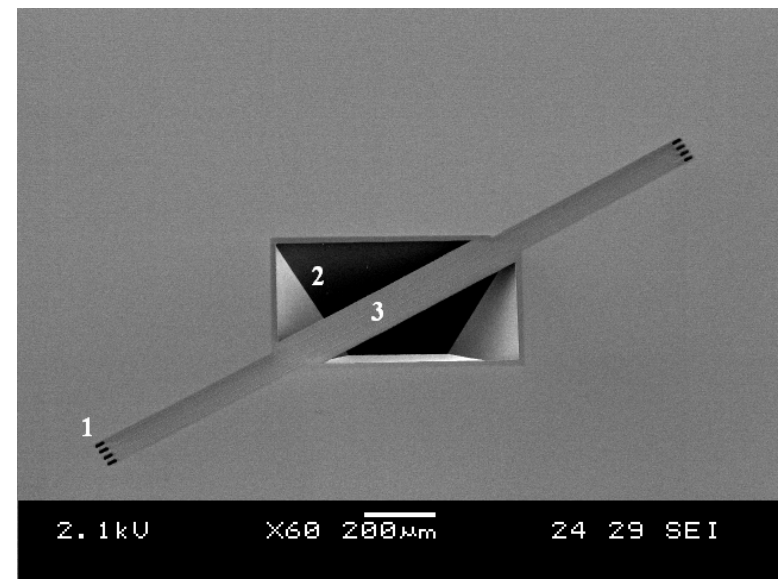

Figure 8. Device structure for thermal flow sensors, with 1) fluid inlet/outlet, 2) thermal isolation cavity and 3) parallel surface microchannels.

Figure 8 shows freely suspended parallel surface microchannels on the frontside of the wafer. The channels are thermally isolated from the substrate by a cavity created by $\mathrm{KOH}$ etching. Capillary tubing connectors can directly be connected to the fluid inlet and outlet, contained below the substrate surface, without introducing large dead-volumes.

The structure can be used for thermal flow sensor applications [1]. Metal heaters and thermocouples can be integrated on top of the freely suspended microchannels. Thermocouple materials can be integrated by releasing the structure with $\mathrm{SF}_{6}$ plasma (figure 4), avoiding compatibility issues with the $\mathrm{KOH}$ etchant.

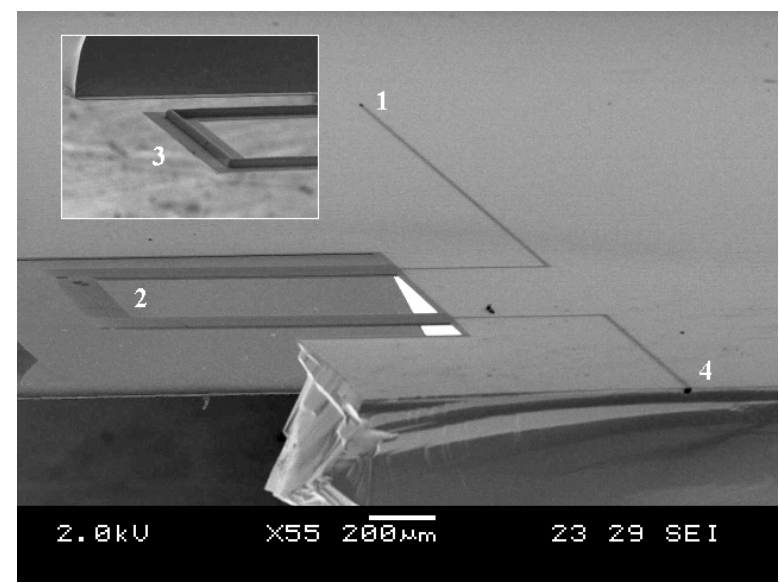

Figure 9. Device structure for fluid-mechanical resonance sensors, with 1) fluid inlet/outlet, 2) fluidic resonance structure, 3) fluidic resonance structure seen from the backside and 4) cross-section of surface microchannel.

Figure 9 shows a $1 \mathrm{~mm}$ long surface microchannel resonance structure broken out of the wafer. The freely suspended surface microchannel is not deflected out-of-plane by possible stress in the $\mathrm{Si}_{\mathrm{X}} \mathrm{N}_{\mathrm{Y}}$ layer. The inherent structural strength of the microchannel might prevent stress from deflecting the resonance structure.

The structure can be used for fluid-mechanical resonance applications [2, 3]. The resonance structure can be excited using electrostatic force, but it should also be possible to integrate a piezoelectric layer, in order to excite and to measure movements of the resonance structure.

\section{CONCLUSIONS}

A versatile concept for the creation of freely suspended surface microchannels using a straightforward and reliable process was demonstrated. With surface channel technology (SCT), microchannels are fabricated directly below the substrate surface, leaving a planar substrate for further processing. The microchannels are released and inlets and outlets are created by a post-processing scheme. The technology allows for easy fluidic interconnection and sensor/actuator integration in close proximity to the fluid.

Several device structures have demonstrated the large freedom of design. Complex microfluidic networks can be created, using a single mask defining etch holes. The microchannels were etched using high-density $\mathrm{SF}_{6}$ plasma with zero self-bias, resulting in good uniformity of the microchannels across the wafer.

\section{REFERENCES}

[1] M. Dijkstra, T.S.J. Lammerink, R.J. Wiegerink, M. Elwenspoek, "Nano-Flow Thermal Sensor Applying Dynamic $\omega-2 \omega$ Sensing Method", Proceeding of MME, 2006.

[2] P. Enoksson, G. Stemme, E. Stemme., “A Silicon Resonant Sensor Structure for Coriolis Mass-flow Measurements”, Journal of Microelectromechanical Systems, Vol. 6, No. 2, 1997

[3] T.P. Burg, S.R. Manalis, "Suspended Microchannel Resonators for Biomolecular Detection”, Applied Physics Letters, Vol. 83, No. 13, 2003

[4] M.-A. Grétillat, et al., "A New Fabrication Method for Borosilicate Glass Capillary Tubes with Lateral Inlets and Outlets”, Sensors and Actuators A, Vol. 60, 1997

[5] M.J. de Boer, et al., "Micromachining of Buried Micro Channels in Silicon", Journal of Microelectromechanical Systems, Vol. 9, No. 1, 2000

[6] J.M. Chong, N.C. MacDonald, “Suspended Moving Channels and Channel Actuators for Microfluidic Applications”, Proceeding of ASME MEMS, Vol. 66, 1998

[7] W. Kaplan, H. Eldersig, C. Vieider., “A Novel Fabrication Method of Capillary Tubes on Quartz for Chemical Analysis Applications”, Proceeding of MEMS, 1994

[8] J. Chen, K.D. Wise, "A High-Resolution Silicon Monolithic Nozzle Array for Inkjet Printing”, Proceedings of Eurosensors, 1995

[9] R.W. Tjerkstra, Isotropic Etching of Silicon in Fluoride Containing Solutions as a Tool for Micromachining, Thesis, University of Twente, 1999 